\title{
PHYSICAL-MATHEMATICAL MODELING OF VIBRATING CONVEYOR DRYING PROCESS OF SOYBEANS
}

\author{
Serhii Kiurchev ${ }^{1}$, Valentyna Verkholantseva ${ }^{1}$, Lyidmila Kiurcheva ${ }^{1}$, Oleksandr Dumanskyi ${ }^{2}$ \\ ${ }^{1}$ Tavria State Agrotechnological University, Ukraine; \\ ${ }^{2}$ State Agrarian and Engineering University in Podilya, Ukraine \\ valentyna.verkholantseva@tsatu.edu.ua,,dakgps@pdatu.edu.ua
}

\begin{abstract}
The parameters of the operating modes of vibration wave transportation of products for infrared drying were determined under the conditions that allow with the minimum energy consumption to provide the maximum productivity of the apparatus, which takes place in the case of providing the desired reduction of the moisture of the bulk mass for one pass of the product flow with a satisfactory uniformity of production. The implementation of these conditions requires synchronization of the operating parameters of the two vibrators of the vibrating conveyor infrared dryer, which are aggregated in the supporting rolls of the deformed transport element. The article deals with determination of regularities of basic parameter change of the infrared drying process, which allows to determine development tendencies of technical and technological efficiency of mechanization means of the high-temperature storage system of seed material of oil-bearing products, which is solved due to use of innovative vibrating conveyor technologies and equipment in the process of vibration, wave, impulse, and combined physical and mechanical factors that make available minimizing energy and material consumption at maximum output maintaining the properties of agricultural raw materials. These measures are implemented through the development of vibration wave inter-operative transportation under the conditions of soybean infrared drying. According to experimental studies, using the "dimension analysis" method and the Federman-Buckingham theorem the criterion equation of the process of mass transfer during drying in the fluidized bed of products has been obtained, which is determined by the criteria of Péclet, Stanton, Bourdieu, a function that characterizes the energy, heat and mass transfer parameters, the performance of the studied process, which allows to form the recommended series when designing conveyor infrared dryers for storage systems of bulk agricultural products.
\end{abstract}

Keywords: vibration, drying, soybean, similarity criteria, process, machine.

\section{Introduction}

The drying process is one of the main and integral stages of high-temperature preservation of crop products in the technological link of the storage system of both seed and food materials [1]. After drying it is possible to significantly increase the shelf life of products, improve the taste and sensory qualities of raw materials, and increase the stability during transportation. However, these processes are some of the most energy-intensive and complex ones in both their mechanisms and technology. The high quality requirements for agricultural products of plant origin, especially seeds, also complicate the design process of efficient dryer models. One of the promising directions for the development of these processes is the infrared ray application in drying. However, modern dryer designs are characterized by relatively large metal and energy consumption, considerable thermal stresses on the upper beds of production and having problems with the uniformity of processing [1;2].

Trends in the development of drying technologies in crop production, in particular when using infrared rays, fundamental theoretical and experimental results, experience and basics of equipment design for their realizations are entrusted to the property of scientific schools and works of such wellknown scientists as Baum A.E., Ginzburg A.S., Goldenberg Y.M., Kudryavtsev I.F., Lykov O.V., Lurie M.Yu., Mikhailov Yu.A., Ptitsyn S.D., Stabnikov V.M., Snezhkin Yu.F [3; 4].

Short-term intense action of the infrared field on the surface layer of raw materials creates problems for it at the same time overheating and uneven layer-by-layer processing. Therefore, it is promising for the transportation of products in the processing area to use conveyor and wave technologies that allow to create favourable conditions for intensification of the production process and application of effective methods of action to its object; implement technological movement in a continuous mode; reduce and eliminate unproductive work, in particular in the implementation of ancillary operations; create general dynamic state control system in which the technological action takes place; minimize mechanical damage to the object.

The combination of vibration and current technologies in conveyor vibrating machines determines the implementation of the highest form of continuity - automation of the production process, 
harmonious ratio of its main structural components, the implementation of effective volumetric action on the product that meets the highest forms of perfection of technological equipment.

The development of vibrating conveyor machines begins with wave and vibrating conveyors, which led to the choice of the subject of research in this scientific work. Fundamental works of I.I. Blekhman, V.O. Povidayla, V.M. Poturaeva, R.I. Silina, A.O. Spivakovsky and other scientists substantiate the theoretical foundations of the vibration movement process and constructive schemes of vibrotransport machines [4].

\section{Materials and methods}

Further search and development of high-temperature preservation systems of seed material during drying occurs by intensification of processes of heat-mass transfer processing with the active use of physical and mechanical factors, in particular, vibration, wave and impulse effects for the maximum preservation of the initial properties of raw materials and moderate energy and material consumption. The drying process can be intensified by changing the bed structure during the transition from dense to loosened, which significantly increases the active surface area of contact with the energy carrier $[3,4]$.

In this regard, it is advisable to apply an oscillatory mode, that is, alternating periods of heating and cooling of the seeds, as well as the creation of a fluidized bed of products when passing the air flow through it, or the application of vibration technologies of bulk mass loosening, which is realized in the dense moveable bed, in a partially suspended state, in the fluidized bed, the fluidized bed and the aerofountain production bed [3].

The objective of this work is to determine the regularities of changing the basic parameters of the vibrating conveyor drying process of soybean seeds using the theory of similarity and the mathematical apparatus of the "dimension theory" on the basis of the experimental study results of the basic thermophysical and mechanical characteristics of the experimental vibrating conveyor infrared dryer with wave vibration transportation of products.

\section{Research and discussion}

The mechanism and intensity of moisture transfer in the material depend on the interconnected complex of processes of breaking the bond of moisture with the material, the diffusion of the vapourgas medium through the capillary-pore material structure etc. Infrared drying allows the radiant flux to be directed partially into the capillary-porous bodies to a depth of $0.1-2 \mathrm{~mm}$ during heat exchange, which is almost completely absorbed by a series of reflections from the walls. In this case, the heat exchange coefficient has a significant value and the length of the drying process in comparison with the convective or conductive method is reduced by 30-100 times [3; 4].

Recently, methods of intensification increasing of heat and mass transfer through the use of a fluidized bed of products, the use of conveyor mechanisms, have been developed. In vibration transport-technological machines of the second type vibration not only reduces the internal friction forces during transportation, but also provides forced vibration movement of the material on the working body under conditions of continuous updating of production beds.

The developed conveyor dryer (Fig. 1) is a combination of a belt conveyor and a vibrating process machine $[4 ; 5]$. Mechanical vibratory drives mounted inside the rollers 1 and 2 due to the presence of an eccentric drive shaft 4 provide a kinematic method of oscillation generation, creating conditions for continuous processing of the product, ensuring its suspended state and reducing the vibrtional masses of the vibrator. The roller 6 provides the necessary tension of the flexible tape. The oscillations of the working rollers with predetermined amplitude and frequency characteristics create a mechanical wave on the surface of the flexible element 3 , which ensures the advance of the bulk production along the treatment zone under the conditions of infrared irradiation.

Loosening the product mass under the influence of alternating loads leads to decreasing the internal friction and viscosity in the process medium, as well as to bed mixing and to ensure a uniform heat treatment of the bulk production [6;8].

Thus, the presented installation allows, first of all, due to the vibromechanical drive to provide the processing facility with the required level of substances and humidity activity; secondly, with the irradiators 5 help realize the necessary energy and technological efficiency of the process; thirdly, 
from the vibrators mounted inside the working rollers, due to mechanical vibration action, 3 waves can be formed on the surface of the tape, which makes it possible simultaneous material transporting and mixing 13.

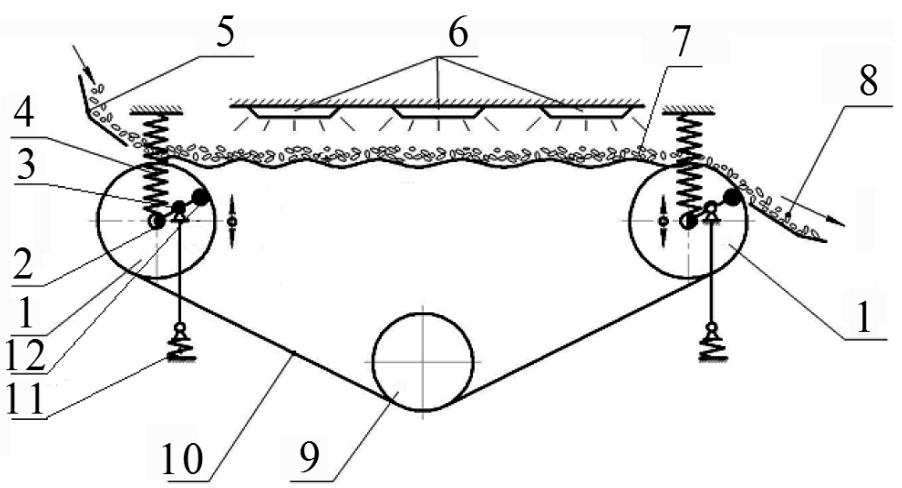

Fig. 1. Infrared dryer with vibrating conveyor element:1, 2 - rollers; 3 - elastic band; 4 - drive vibrator exciter shaft; 5 - emitters; 6 - tensioning roller; 7 - roller axis; 8 - counterweight; 9 - vibration support; 10 - elastic suspension; 11 - receiving seed hopper; 12 - feeder; 13 - seeds

On the basis of the developed dryer scheme an experimental industrial model has been constructed, with the help of which numerical values of the heat-mass transfer parameters of infrared drying in the vibrated soybean bed (Table 1) have been obtained in the course of experimental studies, which allowed to calculate the following basic parameters of the process [7-10].

In order to evaluate the process of high-temperature preservation of oil products using the developed infrared conveyor dryer, a physical and mathematical simulation of this process has been carried out using the 2nd theorem of the Federman-Buckingham's similarity theory and the theory of dimensions $[4 ; 11]$.

On the basis of the experimental database of soybean seed drying, the most significant factor space of the process has been evaluated, among which the following characteristics can be noted: mass transfer coefficient $\beta$; speed of product transportation $V$; thermal conductivity coefficient $\alpha$; power consumption for the process $N_{0}$; soybean kernel diameter $d$; specific heat of vaporization $r$; time of product processing $\tau$; mass of the removed moisture $m_{m} ; \omega-$ angular speed of the drive shaft. The similarity criteria of Stanton St, Reynolds Re, Bourdieu $B u$ and Froude $F r$ have been used to describe this process, which were modified for the process under study as follows:

$$
S t=\beta / V ; R e=V \cdot d / \alpha ; B u=N_{0}\left(\Pi_{v} \cdot r \cdot \rho_{\theta}\right) ; F r=V_{v} \cdot a_{v} g,
$$

where $\Pi_{v}-$ the dryer volumetric capacity;

$V_{v}$-vibration speed;

$a_{v}$-vibration acceleration of the drive vibration wave mechanism.

With the help of the initial data from Table 1 and the presented parameters, the main similarity criteria can be noted, that describe this process in the form of: $P e$ - Péclet number,

where $\alpha=12.6 \cdot 10^{-3} \mathrm{~m}^{2} \cdot \mathrm{s}^{-1}-$ thermal diffusivity coefficient;

$S t=\beta / v-$ Stanton number;

$B u=E_{0} / Q_{B}-$ Bourdieu number;

where $N_{O P}$-emitter power; $N_{n p}$ - drive motor power;

$E_{\mathrm{o}}=N_{\mathrm{o}} \cdot \tau-$ energy consumption on the process;

$Q_{b}=m_{v} \cdot r-$ heat amount required to evaporate the moisture by mass $m_{v}$;

$r=2.3 \cdot 10^{6} \mathrm{~J} \cdot \mathrm{kg}^{-1}$.

The mass transfer coefficient $\beta$ can be determined by the formula where $\Delta x=m_{v} / m_{p}$ - moisture amount removed per unit mass of the dried product, $\mathrm{kg} \cdot \mathrm{kg}^{-1} ; S_{3}=2 \pi d(1+1.5 d)$ - surface area of soybean kernels for sorting oblong seeds $d=5.5-6.5 \mathrm{~mm}$; then we accept $d=6 \mathrm{~mm}$, length $l=8$ $10 \mathrm{~mm} \rightarrow l=9 \mathrm{~mm}: S_{3}=678.24 \cdot 10^{-6} \mathrm{~m}^{2}$; volumetric performance $P_{v}$. 
Initial experimental data of infrared soybean drying in the moving bed

Table 1

\begin{tabular}{|c|c|c|c|c|c|c|c|c|}
\hline No. & $\begin{array}{c}v, \\
\mathbf{c m} \cdot \mathbf{s}^{-1}\end{array}$ & $N_{O P}, \mathbf{W}$ & $\tau, \mathbf{s}$ & $\boldsymbol{m}_{v}, \mathbf{g}$ & $m_{p}, \mathbf{g}$ & $\underset{\mathbf{k g} \cdot \mathbf{k g}^{-1}}{\Delta X,}$ & $\begin{array}{c}m B / \tau, \\
\mathbf{g} \cdot \mathbf{s}^{-1}\end{array}$ & $\begin{array}{c}\tau / m_{v}, \\
\mathrm{~s} \cdot \mathrm{g}^{-1}\end{array}$ \\
\hline 1 & 0.15 & 220 & 85 & 5.1 & 294.90 & 0.017 & 0.0600 & 16.67 \\
\hline 2 & 0.15 & 220 & 205 & 8.1 & 291.90 & 0.028 & 0.0400 & 25.00 \\
\hline 3 & 0.15 & 220 & 380 & 13.8 & 286.20 & 0.048 & 0.0360 & 27.78 \\
\hline 4 & 0.15 & 220 & 520 & 20.4 & 279.60 & 0.073 & 0.0390 & 25.64 \\
\hline 5 & 0.40 & 220 & 45 & 0.3 & 299.70 & 0.001 & 0.0750 & 13.33 \\
\hline 6 & 0.40 & 220 & 84 & 0.9 & 299.10 & 0.003 & 0.0107 & 93.46 \\
\hline 7 & 0.40 & 220 & 160 & 5.1 & 294.90 & 0.017 & 0.0319 & 31.35 \\
\hline 8 & 0.40 & 220 & 235 & 8.7 & 291.30 & 0.030 & 0.0370 & 27.03 \\
\hline 9 & 0.60 & 220 & 50 & 0.45 & 299.55 & 0.002 & 0.0080 & 125.00 \\
\hline 10 & 0.60 & 220 & 95 & 0.75 & 299.25 & 0.003 & 0.0079 & 126.6 \\
\hline 11 & 0.60 & 220 & 140 & 4.2 & 295.80 & 0.014 & 0.0300 & 33.30 \\
\hline 12 & 0.60 & 220 & 320 & 7.2 & 292.80 & 0.025 & 0.0225 & 44.44 \\
\hline
\end{tabular}

Notes: $v$ - speed of transportation of products, $\mathrm{cm} \cdot \mathrm{s}^{-1} ; N_{O P}$ - power of infrared radiation, W; $\tau$ - processing time, $\mathrm{s} ; d W / d t$ - moisture removal rate, $\% \cdot \mathrm{min}^{-1} ; m_{v}$ - mass of the removed moisture, $\mathrm{kg} ; m_{p}$ - mass of the dried product; $\Delta X$ - mass of removed moisture per unit mass of product, $\mathrm{kg} \cdot \mathrm{kg}^{-1}$.

Basic design parameters for infrared soy drying

Table 2

\begin{tabular}{|c|c|c|c|c|c|c|c|}
\hline $\boldsymbol{N}_{\boldsymbol{O P}}, \mathbf{W}$ & $\boldsymbol{\Pi}_{\boldsymbol{v}} \mathbf{1 0}^{-\mathbf{6}} \mathbf{m}^{\mathbf{3}} \cdot \mathbf{s}^{-\mathbf{1}}$ & $\begin{array}{c}\boldsymbol{\beta} \boldsymbol{,} \\
\mathbf{1 0}^{-\mathbf{3}} \mathbf{m} \cdot \mathbf{s}^{-\mathbf{1}}\end{array}$ & $\begin{array}{c}\boldsymbol{v}, \\
\mathbf{\mathbf { c m } ^ { - }} \cdot \mathbf{s}\end{array}$ & $\boldsymbol{S t}$ & $\boldsymbol{P e}$ & $\boldsymbol{B u}$ & $\begin{array}{c}\boldsymbol{F r} \boldsymbol{r} \\
\mathbf{1 0}^{-\mathbf{2}}\end{array}$ \\
\hline $\mathbf{2 2 0}$ & 0.0707 & 6.134 & 0.15 & 4.089 & 71.4 & 1.59 & 1.223 \\
\hline $\mathbf{2 2 0}$ & 0.047 & 2.476 & 0.15 & 1.651 & 71.4 & 2.39 & 1.223 \\
\hline $\mathbf{2 2 0}$ & 0.0424 & 1.302 & 0.15 & 0.868 & 71.4 & 2.66 & 1.223 \\
\hline $\mathbf{2 2 0}$ & 0.046 & 0.93 & 0.15 & 0.62 & 71.4 & 2.45 & 1.223 \\
\hline $\mathbf{2 2 0}$ & 0.088 & 12.97 & 0.4 & 3.24 & 190.5 & 1.275 & 3.26 \\
\hline $\mathbf{2 2 0}$ & 0.0126 & 6.19 & 0.4 & 1.548 & 190.5 & 8.94 & 3.26 \\
\hline $\mathbf{2 2 0}$ & 0.0376 & 3.26 & 0.4 & 0.815 & 190.5 & 2.99 & 3.26 \\
\hline $\mathbf{2 2 0}$ & 0.0436 & 2.138 & 0.4 & 0.5345 & 190.5 & 2.59 & 3.26 \\
\hline $\mathbf{2 2 0}$ & 0.009 & 6.635 & 0.6 & 1.106 & 286 & 11.96 & 4.89 \\
\hline $\mathbf{2 2 0}$ & 0.0093 & 4.571 & 0.6 & 0.762 & 286 & 12.11 & 4.89 \\
\hline $\mathbf{2 2 0}$ & 0.035 & 3.686 & 0.6 & 0.614 & 286 & 3.185 & 4.89 \\
\hline $\mathbf{2 2 0}$ & 0.0265 & 1.563 & 0.6 & 0.2605 & 286 & 4.25 & 4.89 \\
\hline
\end{tabular}

In the simulation, we use the second Federman-Buckingham's similarity theorem, the method of the theory of dimensions for determining degree coefficients for dimensionless complexes of quantities.

The calculated values of the Stanton $S t$, Péclet $P e$, Bourdieu $B u$, Froude $F r$ criteria using the formulas presented above (Table 2) have made it possible to obtain the degree coefficients in the following graphical analytical study by the following method:

- plot the curve of the function $S t=f(P e)$ and determine the angle of inclination to the horizontal axis $\alpha$, from which (Fig. 2): $p=\operatorname{tg} \alpha$ or $p=-\mathrm{g} \alpha=-0.14$;

- plot the curve of the function $S t / P e^{-p}=f(B u)$ and define the angle $\gamma$ in the same way: $m=\operatorname{tg} \gamma=0.55$ (Fig. 3);

- plot the curve of the function $S t /\left(P e^{-p} \cdot B u^{m}\right)=f(F r)$ and determine the angle $\theta$ (Fig. 4) - or $t=-0.5 \operatorname{tg} \theta=-0.5 \cdot 6.3=-3.15$. 


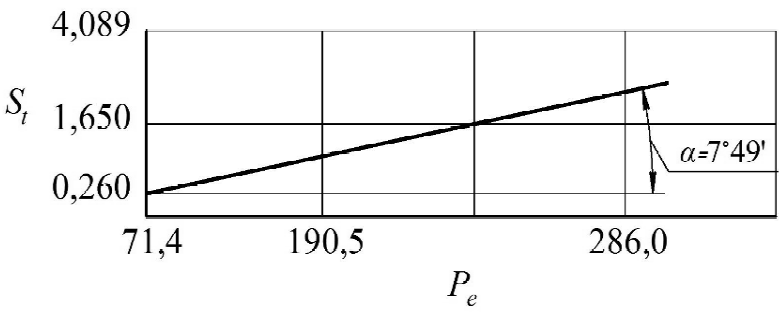

Fig. 2. Relationship between Stanton and Péclet criteria

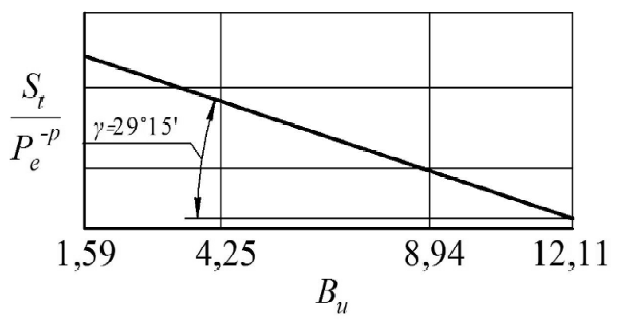

Fig. 3. Relationship between the dimensionless complex $S t / P e^{-0.14}$ and the Bourdieu criterion

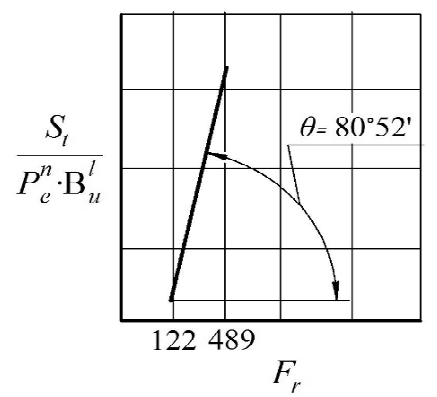

Fig. 4. Relationship between the dimensionless complex $S t /\left(P e^{-0.14} \cdot B u^{0.55}\right)$ and the Froude criterion

With the help of the experimental database and the research graphical analytical method of the similarity theory, the criterion equation of the drying process has been determined in the form of:

$$
S t=A P e^{-p} \cdot B u^{m} \cdot F r^{-t}=A \cdot P e^{-0.14} \cdot B u^{0.55} \cdot F r^{-3.15} \text {. }
$$

The operating mode parameters of vibration wave transportation of products for infrared drying have been determined under the conditions that allow to provide the maximum device productivity with the minimum energy consumption, the productivity takes place in the case of providing the required moisture reduction of the bulk mass for one pass of the product flow with satisfactory uniformity of the production bed. The implementation of these conditions requires synchronization of the operating parameters of two vibrators of the vibrating conveyor infrared dryer, which are aggregated in the supporting rolls of the deformed transport element.

\section{Conclusions}

The scheme and experimental-industrial model of the vibrating conveyor infrared dryer with vibration wave inter-operative transportation of bulk production has been developed, which allows, with the intensification of the moisture removal process, to provide a uniform bed mixing of the bulk mass, preventing the surface bed from overheating and improving the processing quality, transporting it along the work area without the use of additional mechanical devices and, accordingly, reduce energy costs for their implementation. This dryer allows to combine the positive features of the flowing form of processing organization, ensuring the automation of production, the implementation of intensive infrared action in the conditions of the fluidized bed of products, creating energy-efficient and uniform processing of the technological loading mass.

According to the experimental studies, using the method of "dimension analysis" and the Federman-Buckingham's theorem, a criterion equation of the mass transfer process during infrared drying in the moving bed of products, determined by the criteria of Péclet, Stanton, Bourdieu, Froude, a function that characterizes the performance of the process under study, makes it possible to generate the recommended set of operating mode parameters.

With the help of this installation, the speed of product transportation was changed in the range from 0.15-0.6 at constant power. The drying duration also changed depending on the speed of transportation during the drying process. We want to note that a speed of 0.4 most effectively 
contributes to the drying process. That is, with this speed it does not burn and has time to remove moisture.

The designed scheme of the vibrating conveyor infrared dryer ensures, together with the intensification of the moisture removal process, a uniform bed-by-bed mixing of the bulk mass, preventing the surface bed from overheating and improving the quality of processing, transporting it along the working area without the use of additional mechanical devices and, accordingly, reducing energy consumption for high-temperature processing.

\section{References}

[1] Kobets A.S.,Chursinov Yu.O., Chernykh S.A., Sabadash M.P., Grekova N.V., Kanunnikov V.P. Machines and equipment for storage and complex processing of grain. Dnipropetrovsk: SDAU. 2014. 614 p.

[2] Datsyshyn O.V., Tkachuk A.I., Gvozdev O.V., Yalpachik F. Yu., Gvozdev V.A. Technological equipment for grain processing and oil production. Vinnytsia: New Book, 2009. 486 p.

[3] Bezbach I.V., Bakhmutyan N.V. Investigation of the process of drying fruits and berries in a suspended layer // Scientific works of ONAKHT. Odessa: ONAKHT, 2006. Vol. 28, T. 2. p. 112116.

[4] Palamarchuk I.P., Printed M.F., Palamarchuk V.I., Burova S.A. Vibromechanical intensification of drying processes of oil-containing raw materials. K.: NUBiP of Ukraine. - 326 p.

[5] Palamarchuk I.P., Kiurchev S.V., Verkholantseva V.A. Substantiation of parameters of the process of infrared drying of grain products with a vibrating wave conveyor. Scientific works: Sciences. collection. Odessa National Academy of Food Technologies. Odessa, 2018. Vip. 82. T. 1. pp. 122-127.

[6] Palamarchuk I.P., Kiurchev S.V., Verkholantseva V.O. Trends of development of conveyor vibration dryers. The development of technical sciences: problems and solutions: the international research and practical conference (April, 27-28, 2018, Brno city). Brno, 2018. pp. 9-12.

[7] Palamarchuk I.P, Kiurchev S.V., Verkholantseva V.A. Application of vibration technologies in the processes of storage of agricultural products. Import-substitution technologies for growing, storing and processing horticulture and plant production: materials IV Intern. of sciences. practice. Conf. (May 17-18, 2018, Uman). Uman, 2018. pp. 113-115.

[8] Palamarchuk I., Kiurchev S., Kiurcheva L., Verkholantseva V. Analysis of main characteristics of of infrared drying in the moving layer of grain produce. Modern Development Paths of Agricultural Production Trends and Innovations, Part I, Melitopol, Tavria State Agrotechnological University. 2019, pp. 317-322.

[9] Yermakov S., Hutsol T., Ovcharuk O., Kolosiuk I. Mathematic simulation of cutting unloading from the bunker. Independent journal of management \& amp; production (IJM\&amp;P). 2019. pp. 758-777.

[10] Ivanyshyn V., Yermakov., Ishchenko T., Mudryk K., Hutsol T. Calculation algorithm for the dynamic coefficient of vibro-viscosity and other properties of energy willow cuttings movement in terms of their unloading from the tanker. E3S Web of Conferences. Vol.154. 2020. DOI: $10.1051 / \mathrm{e} 3$ sconf/202015404005

[11] Yermakov S., Mudryk K., Hutsol T., Dziedzic K., Mykhailova L. The analysis of stochastic processes in unloadingthe energywillow cuttings from the hopper. Environment. Technology. Resources. Rezekne, Latvia. Proceedings of the 12th International Scientific and Practical Conference. Volume III. 2019. pp. 249-252. 